East." PS: Political Science and Politics 29(4): 696-700.

Voll, John, and John Esposito. 1995. "Islam Has Strong Democratic Traditions." In Islam: Opposing Viewpoints, ed. Paul A. Winters. San Diego: Greenhaven Press. Weiner, Myron. 1987a. "Introduction." In Understanding Political Development, ed. Myron Weiner and Samuel P. Huntington. Boston: Little, Brown and Company. - 1987b. "Political Change: Asia, Africa, and the Middle East." In Understanding Political Development, ed. Myron Weiner and Samuel P. Huntington. Boston: Little, Brown and Company.

Winters, Paul A. ed. 1995. Islam: Opposing Viewpoints. San Diego: Greenhaven Press.
Wolin, Sheldon S. 1968. "Paradigms and Political Theories." In Politics and Experiences: Essays Presented to Michael Oakeshott, ed. Preston King and B. C. Parekh. Cambridge: Cambridge University Press. -. 1969. "Political Theory as a Vocation." American Political Science Review 63(4): 1062-82.

Yazdi, Ayatollah Mohammad. 1997. "The Non-Clergy Do Not Have the Right to 'Interfere' in Politics." Speech Excerpted in Iran Times, July 25, 1.

Zubaida, Sami. 1993. Islam, the People and the State: Political Ideas and Movements in the Middle East. London and New York: I.B. Tauris Publishers.

\title{
Battling the Six Evil Geniuses of Essay Writing
}

\author{
Charles King, Georgetown University
}

Essay questions, term papers, "takehome" finals, research papers, and project reports are standard components of most political science courses. Professors may ask students to write an essay as part of a midterm of final exam, or to hand in extended papers completed outside class that have required substantial research in the university library or elsewhere. These kinds of assignments not only give professors a chance to evaluate students' skills as writers and critical thinkers they also give students a chance to reflect seriously on contentious issues at the heart of the study of politics: What is democracy? What makes people vote for Party A and not for Party $B$ ? Do ideas affect the way people behave politically? Why do revolutions occur? How do states interact in the international arena? What determines the shape of a state's foreign policy? Why do countries go to war?

But university students are smart, sometimes too smart by half. They have learned several tricks of the essay-writing trade and are all too willing to employ them, especially when it comes to answering essay questions on exams. These tricks are thought to be sure-fire techniques for writing essays and getting passing grades, for they have been tried and tested by generations of firstyear college students, including many of the students' professors during their own college days. These tricks are all, however, inspired by one of at least Six Evil Geniuses of Essay Writing. By falling prey to one of the Evil Geniuses, students are guaranteed of getting less than full points for their work; more importantly, signs that the Evil Geniuses are at work normally convince professors that students value getting a passing grade over learning.

Students, especially in introductory courses, should be encouraged to avoid the company of the Six Evil Geniuses and to beware their evil ways. This article exposes the work of these devilishly clever fiends and offers hints for students and professors on how to resist their wiles. Most teaching professionals are already intimately familiar with the Evil Geniuses, either because they have graded essays in which these characters have been at work or, more disturbingly, because they themselves have succumbed to their charms during periods of intellectual weakness. This article presents one framework for addressing some of the key concerns undergraduates have about writing essays in political science courses, a framework which I have used to good effect when teaching my own introductory political science sections.

\section{About the Author}

Masoud Kazemzadeh teaches political science at the University of Alabama at Birmingham. $\mathrm{He}$ is the recipient of the Western Political Science Association's "Best Dissertation in Political Science Award" for 1996. He also received an Honorable Mention from the Foundation for Iranian Studies for the "Best Dissertation of the Year on a Topic of Iranian Studies" (1996). He is the author of Why Khomeini? Class and Gender in the Rise of Islamic Fundamentalism in Iran (forthcoming).

\section{Identifying the Six Evil Geniuses}

The Six Evil Geniuses of Essay Writing come in many different forms, but their main avatars are described below. Examples of each of the Genius's "best" work are also provided.

\section{Evil Genius No. 1: The Sycophant}

The Sycophant thinks that if he butters up the reader-by commenting positively on the lectures or on the reading assignments-the professor will be likely to ignore the content of the essay itself. For example:

Question: Why are political scientists concerned with the concept of "political culture"?

Essay: In their brilliant, path-breaking work, Almond and Verba address the concept of political culture. As Professor Jones demonstrated in her excellent and stimulating lecture, the concept of political culture is important. By using it, as Professor Jones cogently argued, political scientists can explain a number of political phenomena....

Sycophantism is, of course, a bad idea. Essays like this read more like the minutes of a Soviet communist party congress than a response to an exam question. The fact that a professor has assigned a particular read- 
ing during a course is no guarantee that he or she thinks that the author of the reading is "right." Indeed, testing the student's ability to engage critically with assigned readings, instead of merely accepting them as fact because they are written by professional academics, is one of the chief reasons for asking essay questions in the first place.

\section{Evil Genius No. 2: The Rakish Raconteur}

The Rakish Raconteur is the first cousin of the Sycophant. The Raconteur feels that writing in a conversational style and using the essay as a way of "conversing" with the professor will allow her innate wit and charm to mask her lack of knowledge.

Question: Discuss the contrasting views of "modernization theory" and "dependency theory." Which one gives a better account of economic development?

Essay: Well, as I was thinking the other night, modernization and dependency are really two sides of the same coin. I mean, after all, who can say who is more modern than someone else? But seriously (is this a trick question?), there are a couple of ways that one differs from the other. Modernizationists think that the world is linear and ordered (they should see my dorm room!) ....

This student may have a great career selling used cars, but her prospects in any job that requires serious analytical skills are definitely limited. This style is guaranteed to turn off any professor. Essay questions are a tool professors use to assess a student's knowledge and ability to formulate a clear argument. They should not be viewed as a chance to hang out with that lecture dude, know what I'm saying?

\section{Evil Genius No. 3: The Sanitary Engineer}

The Sanitary Engineer (known long ago, in a less politically correct age, as a "garbage man") is an expert at mind-dumping. He has crammed a huge amount of facts, terms, typologies, and other information into his short-term memory, and nothing - not even the essay question itself-will prevent him from getting it all down on paper.

Question: What did Tocqueville mean when he wrote about the importance of "associations" in American civic life?

Essay: Alexis de Tocqueville was a young (26 years old) French traveler and writer who visited America for 9 months in 1831-1832 and wrote a book on his travels, published in two volumes in French in 1835-1840, and in its English translation as Democracy in Amer$i c a$. His purpose in coming to the young United States (in which he visited 17 of the 24 states at the time), which had engaged in a revolution with Great Britain over a half century before and had adopted an independent Constitution, was actually to write a report on the American prison system. He traveled with an associate, Gustave Beaumont (see map and sketch of Beaumont on next page),....

Of course, it is always a good idea to let the reader know that one has full command of the facts, but throwing in a congeries of irrelevant factoids without addressing the question at hand is never helpful. The Sanitary Engineer has accumulated a great deal of information, and his ability to recall it all is certainly impressive. But while his skills might be useful in a game of Trivial Pursuit, they will not necessarily help him answer the essay question.

\section{Evil Genius No. 4: The Jargon-Meister}

The Jargon-Meister attempts to blind the reader with science. Using an array of political science termsmost of which he probably does not understand-he hopes to lull the reader into a state of social science ecstasy. In such a state, the JargonMeister thinks, the professor will ignore the fact that the essay really says nothing at all.

Question: What do some theorists mean when they say that humans are "rational actors"?

Essay: Rationality is an exogenous component of selective incentives. As such, and in direct contradiction to the concept of endogeniz- ing preferences, actors cannot be truly rational unless they have engaged in side-payments to rotating credit organizations. This gives Mancur Olson a collective action problem from which he cannot reasonably recover....

The Jargon-Meister appears to make an argument-and a forceful one at that. But once one peels away the terminology, it is clear that the essay really has very little content. Political science, like all academic disciplines, has its own particular language; complex concepts and ideas are expressed through terms and phrases that sometimes appear impenetrable to the uninitiated. Learning to wield these terms effectively is part of doing political science well, but their use should not get in the way of making a clear and accessible argument.

\section{Evil Genius No. 5: The Bait-and- Switch Artist}

The Bait-and-Switch Artist is a master of prestidigitation. She engages in a sleight-of-hand in which she substitutes a new essay question for the one that appears on the page-and poof! the original essay question magically disappears. Her calling card is the word "while."

Question: Evaluate Theda Skocpol's argument on the origins of social revolutions.

Essay: While Theda Skocpol makes many interesting and important arguments about the origins of social revolutions, the concept of political culture is also extremely relevant. Political culture can be defined as the array of beliefs and norms in a given society about the legitimacy of political actors and political institutions....

The Bait-and-Switch Artist may go on to write a brilliant essay, but not one that answers the question that was originally asked. Of course, highlighting one's knowledge in particular areas is a useful strategy when writing exam essays, but if the response provided fails to address the question asked, even the most insightful essay will not receive much attention from the professor. 


\section{Evil Genius No. 6: The Knee-Jerk} Nihilist

The Knee-Jerk Nihilist is the most sophisticated, most dangerous, and most evil of the Geniuses. He has probably taken an introductory course in literary theory, quantum physics, or postmodernism, but has forgotten most of what he learned. The one thing he took away from these courses, though, was a fundamental conviction that the world around us is just too complicated and too contradictory for us to make any sense of it. He also believes that because all our judgments are clouded by our own prejudices, anyone's opinion is just as good as anyone else's. The Knee-Jerk Nihilist is often seen wearing black and reading Nietzsche. He is also fond of quotation marks.

Question: What makes a political system democratic?

Essay: Democracy is a relative concept. In fact, the concept of "concept" is also relative. Words mean whatever we want them to "mean," and this is especially true for "democracy." For some, it means "free" elections. For others, it means keeping your own thugs "in power" and keeping the enemy thugs "out of power." No one can ever give a coherent definition, because it always depends on the "context." And since the "context" is always shifting, the "concept" of "democracy" also shifts ....

The Knee-Jerk Nihilist is smart. He has read a great deal and thought seriously about issues. $\mathrm{He}$ has become so disillusioned about the possibility of our arriving at any real understanding of the world, however, that he has mortgaged his powers of analysis for a modish slavery to intellectual skepticism.

\section{Battling the Six Evil Geniuses}

How can students exorcise the Six Evil Geniuses? On their own, they probably can't. In the rush to finish exam essays in the allotted time, the temptations of the Geniuses can often lead even the most steadfast students astray. Fortunately, though, there are several practical ways professors can assist students in their battles with these diabolical forces.

The Evil Geniuses are most likely to appear the moment students gaze upon a sheet of essay questions and begin to think about the enormity of the task before them. In tackling essay questions on timed exams, students often face three problems:

- First, some students may feel that they just do not know where to begin: "How can I answer a question that's so broad? I just don't have enough information."

- Second, even if they feel they know something about the subject, students may wonder how to organize the information in order to present a coherent and convincing argument: "How do I begin to put together all the various pieces to the puzzle so that what I say makes sense?"

- Finally, students may be unsure about the relationship between the presentation of factual information and the expression of their own views on the issue at hand: "The professor never told me whether he wanted me to repeat what he had said in class, or if he was just looking for my opinion."

Clearly, professors have their own individual (and sometimes idiosyncratic) views on the place of essays and other writing assignments in university education. But the ideas presented below can help students improve their essay-writing skills, particularly their ability to write clear and convincing essays on timed exams. In my undergraduate classes, the use of the Evil Geniuses framework has helped students become more aware of the rhetorical techniques that they use in their own writing; by self-consciously addressing questions of form and style of argumentation early on in the course, using the ideas outlined below, many students have been able to fend off the Geniuses when they inevitably come calling.

Start at the Beginning When students first read an essay question on an exam (or begin to think about an assigned topic for a term paper or take-home final), they should ask themselves two sets of questions:

What does the essay question really say? What kinds of issues is it asking me to address? What assumptions lie behind the question itself?

Professors ask essay questions for a reason. They use essays as a way of getting students to go beyond the material presented in class and in the required readings for the course. They normally intend for students to reflect critically on the information they have received, assess its validity, think about its implications, and use it creatively in order to answer the question that has been posed.

Spending a few minutes thinking about what the question really asks is therefore crucial to exam success. In fact, it is the student who fails to analyze the question who will be most susceptible to the charms of Evil Genius No. 3, the Sanitary Engineer, whose motto is always "Thinking wastes time; just start writing." At the same time, though, most professors are not looking simply for an extended analysis of the question itself, a strategy often followed by Evil Genius No. 6, the Knee-Jerk Nihilist, who spends so much time picking apart the question that he never gets around to answering it. It is often said that writing a good essay question is as difficult as writing a good essay; while most professors would probably find an essay that addresses the shortcomings of the question itself a useful and welcome form of feedback, those essays that never move beyond a critique of the question are unlikely to receive full marks.

What are the most useful sources of information on which I can draw in order to answer the question? What kinds of data will best support my argument?

During any semester-long course, students encounter a huge amount of information, both factual and conceptual. Influenced by Evil Geniuses Nos. 3 and 4, the Sanitary Engineer and the Jargon-Meister, many students treat essay questions as dumping grounds for the information that they acquired in the days and weeks preceding the exam. They pile on 
fact after fact, concept after concept, date after date, name after name, with little thought about whether all this information helps them answer the question. "If $I$ throw in enough stuff," a student may say, "at least the professor will know that I've been paying attention." Wrong. The professor will know that the student managed to cram a great deal of irrelevant information into her shortterm memory. But whether she has really thought about the issues at hand, i.e., used her knowledge to reflect critically on an important question in political science, will remain a mystery.

After the student has determined the general kind of response that the essay question is trying to elicit, she should ask herself which bits of information will be the most relevant and most helpful in supporting the essay's overall argument. After doing the reading and attending the lectures, students certainly have enough information to answer the question effectively. The crucial task, though, is to organize the information and to present it in a way that buttresses the essay's main theme.

Organization Is Everything, Almost. Because they have not stopped to ask themselves the questions above, many students plunge right into an essay without thinking about how to organize their thoughts. "If I just get enough stuff down on paper," a student might argue, "then the professor will at least know that I've tried to answer the question." Wrong again. The professor will know that Evil Geniuses Nos. 2 and 3, the Rakish Raconteur and the Sanitary Engineer, are at work, not that the student has thought seriously about the question.

Once the student has determined what the question is asking and has spent a few minutes reflecting on the kinds of information that would be useful in attempting to answer it, he should then spend some time sketching out the form that the essay will take.

Make an Outline. The student might be encouraged to sketch out the structure of the essay, perhaps in the exam booklet itself, in the form of a brief outline, flow chart, diagram, or whatever form she finds most helpful in organizing her thoughts. The important thing is to have a clear idea of what she wants to say and how she is going to say it before she begins writing.

There is an additional advantage to writing an outline or essay plan. It may turn out that the student simply budgeted her time poorly and did not have time to complete the entire essay as planned. If the professor sees that the student had a clear vision of what she wanted to argue, she may receive at least some credit for the incomplete essay. On the other hand, if she managed to fill up a dozen pages without making a coherent argument-a strategy encouraged by several of the Evil Geniuses-chances are that the professor will remain relatively unimpressed.

Keep It Simple. No one really learns everything he needs to know in kindergarten, but students do often forget important writing techniques that they learned in grade school. One of those is what, in bygone days, used to be called a "three-point enumeration." This form of essay-writing consisted of an opening paragraph, three further substantive paragraphs and a conclusion. The opening paragraph set out the general ideas that would be explored, the three following paragraphs expanded on each of those ideas, and the final paragraph wrapped up what the essay said.

The same format-with perhaps some modifications - can be used to write responses to essay questions. The opening paragraph should state clearly the main point the student wishes to make in the essay. Someone should be able to read the first sentence and know exactly how the student plans to answer the question. Being too cute is never a good idea-the advice of Evil Genius No. 1, the Sycophant, notwithstanding but a catchy opening sentence which states simply and clearly the line of argument the student intends to take is always desirable. Other sentences in the first paragraph should then support the first sentence and sketch out the ways in which subsequent paragraphs will expand on the theme of the essay itself. Next, in the body of the essay, each paragraph should make a clear and discrete point, and that point should support the overall argument. The concluding paragraph should summarize what the student has said in the preceding paragraphs and remind the reader of the main argument. All Americans want closure, even on exam essays.

\section{Political Science Is Not Just "A Matter of Opinion."}

Essay questions are not extended short-answer questions. A professor puts essay questions on exams to solicit a student's informed views on a particular subject that should have been mastered in the course, not to see if the student can repeat verbatim what the professor said in class. In this sense, essay questions do ask for students' "opinions," but they are opinions that, after being shaped by information presented in the course, should be intelligent, informed, and well-structured. No conceptual questions in political science have onceand-for-all answers. Essay questions ask students to address important issues by using their brains-constructing a coherent, logical, and informed view on a given topic. After sitting in a course of lectures and doing the required reading, any university student should be more than capable of completing such a task. A student's "opinion" should have evolved and become more sophisticated, and she should have developed a reasonable level of expertise in the main issues addressed during the course itself. Her "opinions" matter, for they were what the professor was trying to get her to develop all along.

Again, contrary to the mantras of several of the Evil Geniuses, essays are not simply receptacles for regurgitated factual information. Students' knowledge of facts can be assessed using multiple-choice, true/false, identification, definition, shortanswer, and a range of other examination question formats, most of which they encountered in grade school. At the college level, however, students are expected to think, and thinking requires creatively using the knowledge they have acquired to take a clear position on a contentious issue.

How do they do all that? First, they should be encouraged to make 
an argument, take a stance, stake out a position. Simply reeling off dates and names, using political science jargon, or writing as much as possible in the hope that something intelligent will bubble through will not do the trick. Second, they should support their argument with relevant facts, concepts and other information that relate directly to the essay question. Irrelevance, even if it comes in volume, is still irrelevance. It clouds the argument and ultimately convinces the professor that the student really has no idea what he is talking about. Third, how creatively a student makes an argument is always important. Style matters. Some professors may even prefer essays that are well-structured and well-written but not particularly brilliant, to those that contain a truly original insight cloaked in language that would make Webster and Fowler turn in their graves. Writing a sonnet or a short one-act play is not usually a good idea, but a student should be encouraged to bring all his skills as a writer to bear on the essay topic. After all, that is why the question is an essay question, rather than a true/false or short-answer. Finally, an essay must answer the question, a point which is often forgotten as students fall victim to Evil Geniuses Nos. 3 and 5, the Sanitary Engineer and the Bait-andSwitch Artist. If a student writes page after page of text, but never really addresses the issue at hand, few professors will be likely to award much credit.

\section{Vigilance and Intellectual Honesty}

The Six Evil Geniuses come in myriad guises, but avoiding them and their ilk is essential to writing quality essays. Although the Evil Geniuses are most likely to strike during timed exam essays, they can also sometimes be found hovering around take-home exams and term papers. In any of these instances, the chief antidote to an Evil Genius is intellectual honesty. Reading the essay question critically or spending time thinking hard about a paper topic, and then mustering one's intellectual resources to approach hon- estly and openly the task of writing a response are the most important ways of combating the lure of the Evil Geniuses. They can sometimes be hard to resist but, like for Ulysses lashing himself to the mast, the reward of steadfastness is survival. By understanding the wiles of the Evil Geniuses of Essay Writing and taking steps to resist their temptations, students can improve their ability to write clear and powerful essays that will help them organize their thoughts and deepen their understanding of key issues in political science. And that, after all, is why they signed up for the course in the first place.

\footnotetext{
About the Author

Charles King holds the Ion Ratiu Chair of Romanian Studies at Georgetown University. $\mathrm{He}$ is coeditor, with Neil Melvin, of Nations Abroad: Diaspora Politics and International Relations in the Former Soviet Union (forthcoming), and is the author of numerous articles and book chapters on nationalism, the Balkans, Romania, and other subjects.
} 